\title{
Negative correlation between concentration of iron oxides and particulate matter in atmospheric dust: case study at industrial site during smoggy period
}

\author{
Eduard Petrovský * $^{*}$, Aleš Kapička ${ }^{1}$, Hana Grison ${ }^{1}$, Bohumil Kotlík ${ }^{2}$ and Hana Miturováa
}

\begin{abstract}
Background: Environmental magnetism, focusing on ferrimagnetic iron oxides, provides useful additional information on pollution of different environments. Magnetic methods have been applied to studies of atmospheric dust, namely PM10 (particulate matter smaller than $10 \mu \mathrm{m}$ ) in, e.g., industrial or urban areas. Until now, positive correlation was reported between concentration of iron oxides (expressed in terms of either magnetic susceptibility, saturation remanent or saturation induced magnetization) and concentration of PM10 or smaller. Purpose of this study was to verify the relationship between iron oxides and PM at monitoring site close to source of emissions rich in iron oxides during period of smoggy conditions.
\end{abstract}

Results: We examined 24-h PM10 and PM1 samples, collected during 10 days of smoggy winter period at a site close to steel plant, which represents a significant source of atmospheric emissions in industrial region of Northern Moravia (Czech Republic), known for generally high degree of air pollution. Magnetic hysteresis loops were measured to obtain parameters reflecting the concentration and grain-size distribution of iron oxides. Our data show unexpected negative correlation between saturation magnetization (concentration of ferrimagnetic iron oxides) and both PM1 and PM10 concentrations, to the best of our knowledge the trend not being reported yet.

Conclusions: Our finding may seemingly disqualify magnetic methods as useful proxy in air pollution studies. However, we suggest that this is an exceptional case, specific to this region and monitoring site, as well as to synoptic conditions during the smoggy period. Although the significant dust emissions are presumably rich in iron oxides, the overall air quality at the monitoring site is determined by the general environment, controlled by many other sources of different character in the region, and by the specific climatic conditions. Thus, the steel plant, presumably emitting dust rich in ferrimagnetic iron oxides, dominates the deposited dust at the nearby monitoring site only during few days of suitable weather (namely wind speed and direction).

Keywords: Environmental magnetism, Magnetite, Atmospheric dust, Particulate matter, Pollution, Steel works, Correlation

\footnotetext{
*Correspondence: edp@ig.cas.cz

${ }^{1}$ Institute of Geophysics, Czech Academy of Sciences, Boční II/1401,

14100 Prague 4, Czech Republic

Full list of author information is available at the end of the article
}

\begin{abstract}
Background
Environmental magnetism applies rock-magnetic methods to assess the composition, concentration, and grain-size distribution of ferrimagnetic iron oxides, namely magnetite and maghemite. Originally developed for the study of historical records of geomagnetic field and its changes in rocks (paleomagnetism), these methods are now also
\end{abstract}


used to study magnetic properties of, e.g., sediments, soils, atmospheric dust and its biocarriers (tree leaves and needles, lichens, mosses), mainly to establish the correlation between magnetite (and/or maghemite) and environmentally significant parameters, such as concentration of heavy metals or particulate matter of specific size (PM10), and thus to assess the environmental stress reflected by the presence of these minerals. Muxworthy et al. [1] investigated samples of respirable atmospheric particulate matter collected in Munich, Germany, and compared them with pollution and meteorological data. The primary magnetic mineral identified was magnetite in the grain-size range $0.2-5 \mu \mathrm{m}$ and concentrations of $0.3-0.6 \%$ in mass. Saturation remanent magnetization $\left(M_{\mathrm{rs}}\right)$ of daily samples of PM10, collected at two sites in Munich, Germany, was found to be strongly correlated with the PM mass, with the magnetite concentration being $0.3-0.5 \%$ by mass [2]. Magnetite as the dominant magnetic mineral was identified in particulate matter $10 \mu \mathrm{m}$ or less in diameter (PM10) collected at sites with different level of air pollution also by Petrovsky et al. [3]. Sagnotti et al. [4] reported on the magnetic properties of PM10 samples collected by six automatic stations installed for air quality monitoring through the Latium Region (Italy). In addition to magnetic parameters reflecting the composition, concentration and grain-size distribution of iron oxides, Sagnotti et al. [4] examined also low-field magnetic susceptibility and found high positive correlation with PM10. More details on composition, concentration and grain-size distribution of magnetic fraction deposited on tree leaves as well as collected by automated monitoring station in Rome were published by Sagnotti et al. [5]. Magnetic properties of tree leaves as biocarriers of the deposited atmospheric dust have been investigated in relation to air pollution by many authors [5-17]. There are also numerous studies on magnetic properties of tree needles [18-20], tree barks, rings or branches [21-26], lichens, in situ or transplanted [27-34], and moss and transplanted moss bags [32, 35-42]. High sensitivity of magnetic methods enabled even examination of magnetic properties of spider webs [43]. Magnetic measurements of different carriers of atmospherically deposited dust particles have unambiguously several advantages: very high sensitivity in terms of concentration of ferrimagnetic iron oxides, non-destructive character, ability to investigate short-term (daily samples) as well as long-term deposition (months to years), and/or possibility to be applied in remote places without any infrastructure and electricity (transplanted lichens and moss bags). However, it has to be emphasized that the results in terms of air pollution are site specific; correlation with environmentally important parameters has to be established for each study site independently. It seems also clear that saturation magnetization (either remanent or induced) is more sensitive and reliable magnetic parameter compared to magnetic susceptibility, the use of the latter one as a rapid method of assessing the bulk magnetic content of atmospheric particulate matter could be misleading.

Finally, to the best of our knowledge, all the studies reported on positive correlation between concentration of ferrimagnetic iron oxides and particulate matter, either PM10 or smaller. In this study, we examine daily PM10 and PM1 samples collected by automatic high-volume samplers at industrial monitoring site located very close to the iron smelter during smoggy period, characterized by very high level of air pollution. Magnetite was determined as the main magnetic fraction in PM10 collected at the same monitoring station in our previous study [3]. The aim of the present study was to determine the relationship between concentration of magnetite and PM at this specific industrial site, where we assumed that magnetite is predominantly of industrial origin, emitted from the steel plant. Moreover, due to the specific climatic conditions during the smoggy period, the emitted dust is supposed to remain in the close neighborhood of the source.

\section{Samples and methods}

Daily samples of PM10 and PM1 (16 samples each) were collected from 30 January to 7 February 2012 using two parallel Grasseby-Andersen high-volume samplers during day and night time (thus representing 12-h accumulation) on acetyl-nitrocellulose filters at monitoring station "Ostrava Radvanice ZU" (formerly Ostrava Bartovice, GPS $49^{\circ} 48^{\prime} 25.4^{\prime \prime} \mathrm{N} 18^{\circ} 20^{\prime} 20.9^{\prime \prime} \mathrm{E}$, altitude of $263 \mathrm{~m}$ a.s.l., Fig. 1). This period was characterized by smoggy conditions, with PM10 daily average concentrations well above $50 \mu \mathrm{g} / \mathrm{m}^{3}$ (Table 1 ). After this period, when the daily PM10 values dropped below the limit of $50 \mu \mathrm{g} / \mathrm{m}^{3}$, additional sampling from 16 to 18 February was carried out to obtain samples for comparison (4 samples of both PM10 and PM1).

Mass of the deposited dust (PM10 and PM1) was determined by subtracting the mass of blank filter (before the exposure in the high-volume samplers) from the mass of filter with collected PM (after the exposure). Subsequently, the mass of PM was divided by the volume of air which flew through the sampler to obtain the concentration of PM in $\mu \mathrm{g} / \mathrm{m}^{3}$.

The station belongs to automatic monitoring network of the Czech Hydrometeorological Institute (www.chmi. $\mathrm{cz}$ ). It is located in residential area, about $50 \mathrm{~m}$ from major road and some few hundreds of meters from major steel works to the south-west (Fig. 1). According to the EOI 97/101/EC document (https://eur-lex.europa.eu/ legal-content/EN/TXT/PDF/?uri=CELEX:31997D0101 \&from $=\mathrm{EN}$ ), the station is classified as industrial, and the 


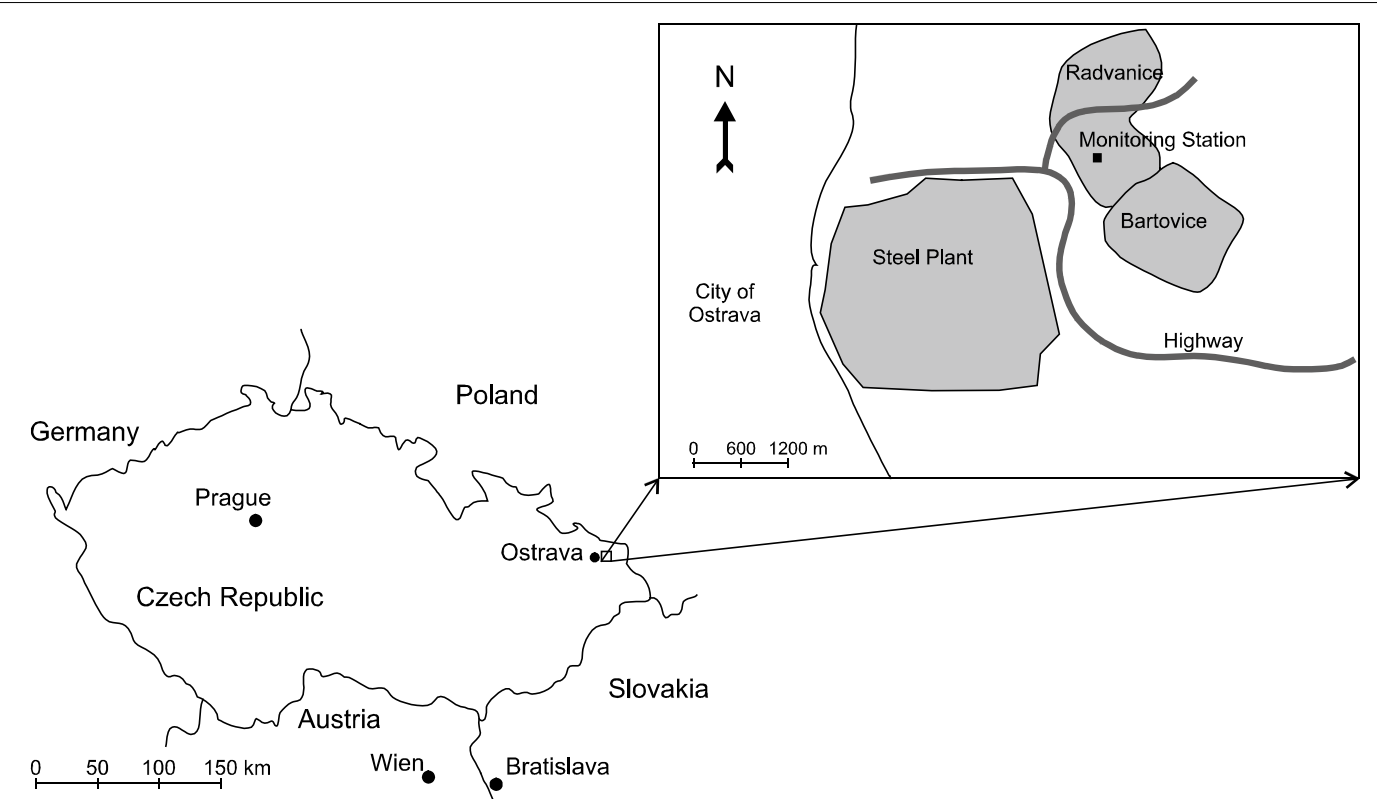

Fig. 1 Location of the study site. The detail shows positions of the steel plant and Radvanice and Bartovice suburban areas in relation to the monitoring station

zone is characterized as industrial/suburban/residential (https://portal.chmi.cz/files/portal/docs/uoco/web_ generator/locality/pollution_locality/loc_TORE_ GB.html). The spatial representativeness of the station is within the microscale of $100 \mathrm{~m}$. The site is considered as one with the most polluted atmosphere in the Czech Republic. In 2012, the maximum of daily average concentration of PM10 was $281.3 \mu \mathrm{g} / \mathrm{m}^{3}$, median was $35.2 \mu \mathrm{g} / \mathrm{m}^{3}$, the daily limit of PM10 was exceeded during 166 days. The annual average concentration of PM10 was $49.5 \mu \mathrm{g} / \mathrm{m}^{3}$ (data based on automatic monitoring using the optoelectronic method, [44]). Data for PM1 are not available for that period, only PM10 and PM2.5 were monitored automatically. The sampling period of February 2012 was characterized by smoggy conditions; the daily limit of PM10 was consistently exceeded from 24 January until 21 February (Table 1). The average daily PM10 concentrations during January and February 2012 ranged from 15.9 to $281.3 \mu \mathrm{g} / \mathrm{m}^{3}$ (automatic monitoring system, optoelectronic method, www.chmi.cz).

Magnetic properties were measured using ADE EV9 vibrating sample magnetometer (DSM Magnetics, ADE Corporation; Lowell, MA, USA) at room temperature. Hysteresis loops (induced magnetization) were measured in magnetic fields from -2 to $+2 \mathrm{~T}$. To define the intersections with the field and magnetization axes using linear interpolation (coercive force $B_{c}$ and saturation remanent magnetization $\mathrm{M}_{\mathrm{r} s}$, respectively), the field step varied from 0.5 to $50 \mathrm{mT}$ for different sections of the loop, the finest field step was used around the intersection with the magnetization axis. From each sample, a specimen $1 \mathrm{~cm}$ wide and $10 \mathrm{~cm}$ long was cut, carefully folded and attached to the quartz sample holder using teflon tape. The measured magnetic moment represents a combination of different responses: that of diamagnetic substance of the filter and quartz sample holder, and diamagnetic, paramagnetic and ferrimagnetic minerals contained in the dust. To obtain only the signal corresponding to ferrimagnetic minerals (presumably magnetite), first background curve of the blank filter was subtracted from the measured data. Then, combined contribution of paramagnetic and diamagnetic minerals present in the specimen to total magnetic moment was determined by linear regression fit above $1 \mathrm{~T}$. At these fields, ferrimagnetic contribution is already saturated and does not contribute to further increase of total magnetic moment. Subtracting this linear trend from the measured magnetic moment (Fig. 2) results in data representing only ferrimagnetic response to the applied magnetic field. In order to obtain magnetization, the measured data were normalized by mass of the measured dust $\mathrm{m}_{\mathrm{MD}}$, which was determined as follows:

$$
m_{\mathrm{MD}} \approx\left(m_{\mathrm{SP}} / m_{0}\right) m_{D},
$$

where $m_{\mathrm{SP}}$ is mass of the measured specimen, $m_{0}$ is mass of the original sample (whole filter and deposited dust), and $m_{\mathrm{D}}$ is mass of the dust deposited on the whole filter. 
Table 1 List of particulate matter (PM) sample codes, corresponding sampling time and average daily concentration of PM10, and meteorological data

\begin{tabular}{|c|c|c|c|c|c|c|c|c|c|}
\hline \multicolumn{2}{|c|}{$\begin{array}{l}\text { Specimen } \\
\text { code }\end{array}$} & \multicolumn{2}{|c|}{ Sampling period } & \multirow[t]{2}{*}{$\mathrm{PM} 10\left[\mu \mathrm{g} / \mathrm{m}^{3}\right]$} & \multirow[t]{2}{*}{$\begin{array}{l}\text { Air pressure } \\
{[\mathrm{hPa}]}\end{array}$} & \multirow[t]{2}{*}{ Humidity [\%] } & \multirow[t]{2}{*}{$\begin{array}{l}\text { Temperature } \\
{\left[{ }^{\circ} \mathrm{C}\right]}\end{array}$} & \multirow{2}{*}{$\begin{array}{l}\text { Wind } \\
\text { speed } \\
{[\mathrm{m} / \mathrm{s}]}\end{array}$} & \multirow[t]{2}{*}{ Wind direction } \\
\hline PM10 & PM1 & Start & End & & & & & & \\
\hline G180 & G181 & $\begin{array}{c}\text { 30/01/2012 } \\
09: 00\end{array}$ & $\begin{array}{c}30 / 01 / 2012 \\
19: 00\end{array}$ & 121.8 & 1031.0 & 65.7 & -10.3 & 1.7 & NE (ENE) \\
\hline G178 & G179 & $\begin{array}{c}30 / 01 / 2012 \\
19: 00\end{array}$ & $\begin{array}{c}31 / 01 / 2012 \\
07: 00\end{array}$ & & 1030.8 & 78.3 & -13.9 & 1.0 & NE (ENE) \\
\hline G176 & G177 & $\begin{array}{c}31 / 01 / 2012 \\
07: 00\end{array}$ & $\begin{array}{c}31 / 01 / 2012 \\
19: 00\end{array}$ & 131.5 & 1029.4 & 71.6 & -12.8 & 1.4 & NE (ENE) \\
\hline G174 & G175 & $\begin{array}{c}31 / 01 / 2012 \\
19: 00\end{array}$ & $\begin{array}{c}01 / 02 / 2012 \\
07: 15\end{array}$ & & 1028.4 & 75.7 & -14.1 & 0.9 & $\mathrm{NE}$ \\
\hline G172 & G173 & $\begin{array}{c}01 / 02 / 2012 \\
07: 45\end{array}$ & $\begin{array}{c}01 / 02 / 2012 \\
19: 00\end{array}$ & 103.5 & 1028.6 & 70.3 & -14.2 & 2.2 & $\mathrm{NE}$ \\
\hline G170 & G171 & $\begin{array}{c}\text { 01/02/2012 } \\
19: 00\end{array}$ & $\begin{array}{l}02 / 02 / 2012 \\
07: 00\end{array}$ & & 1028.9 & 76.8 & -16.8 & 1.7 & $\mathrm{NE}$ \\
\hline G168 & G169 & $\begin{array}{c}\text { 02/02/2012 } \\
08: 00\end{array}$ & $\begin{array}{c}02 / 02 / 2012 \\
19: 00\end{array}$ & 228.7 & 1029.2 & 71.8 & -15.6 & 1.4 & $\mathrm{~N}$ \\
\hline G166 & G167 & $\begin{array}{c}02 / 02 / 2012 \\
20: 00\end{array}$ & $\begin{array}{c}\text { 03/02/2012 } \\
07: 00\end{array}$ & & 1029.7 & 78.5 & -17.7 & 0.9 & NE (ENE) \\
\hline G164 & G165 & $\begin{array}{c}\text { 03/02/2012 } \\
07: 00\end{array}$ & $\begin{array}{c}\text { 03/02/2012 } \\
19: 00\end{array}$ & 180.6 & 1030.0 & 63.7 & -16.0 & 1.8 & NE (ENE) \\
\hline G162 & G163 & $\begin{array}{c}\text { 03/02/2012 } \\
19: 00\end{array}$ & $\begin{array}{c}\text { 04/02/2012 } \\
07: 00\end{array}$ & & 1031.7 & 73.3 & -18.2 & 1.3 & NNE \\
\hline G160 & G161 & $\begin{array}{c}\text { 04/02/2012 } \\
07: 00\end{array}$ & $\begin{array}{l}\text { 04/02/2012 } \\
\text { 19:00 }\end{array}$ & 147.4 & 1031.2 & 67.5 & -16.4 & 1.7 & NNE \\
\hline G158 & G159 & $\begin{array}{c}\text { 04/02/2012 } \\
19: 00\end{array}$ & $\begin{array}{c}\text { 05/02/2012 } \\
07: 00\end{array}$ & & 1030.5 & 64.1 & -15.0 & 1.5 & NE (NNE) \\
\hline G156 & G157 & $\begin{array}{l}\text { 05/02/2012 } \\
07: 00\end{array}$ & $\begin{array}{l}\text { 05/02/2012 } \\
19: 00\end{array}$ & 127.1 & 1030.2 & 58.0 & -13.2 & 2.1 & NE (ENE) \\
\hline G154 & G155 & $\begin{array}{c}\text { 05/02/2012 } \\
19: 00\end{array}$ & $\begin{array}{c}\text { 06/02/2012 } \\
07: 00\end{array}$ & & 1029.9 & 74.6 & -15.5 & 1.2 & NNE (ENE) \\
\hline G152 & G153 & $\begin{array}{c}\text { 06/02/2012 } \\
07: 00\end{array}$ & $\begin{array}{c}\text { 06/02/2012 } \\
19: 00\end{array}$ & 141.7 & 1028.8 & 72.8 & -14.5 & 1.7 & N (NNW, NNE) \\
\hline G150 & G151 & $\begin{array}{c}06 / 02 / 2012 \\
19: 00\end{array}$ & $\begin{array}{c}\text { 07/02/2012 } \\
07: 00\end{array}$ & & 1028.0 & 74.5 & -13.6 & 2.2 & NE (NNE) \\
\hline G148 & G149 & $\begin{array}{l}16 / 02 / 2012 \\
09: 00\end{array}$ & $\begin{array}{l}16 / 02 / 2012 \\
19: 00\end{array}$ & 49.5 & 1013.8 & 83.0 & -2.9 & 1.8 & NNW \\
\hline G146 & G147 & $\begin{array}{c}16 / 02 / 2012 \\
19: 00\end{array}$ & $\begin{array}{c}17 / 02 / 2012 \\
07: 00\end{array}$ & & 1016.5 & 84.6 & -3.1 & 1.4 & W (NW, WSW) \\
\hline G144 & G145 & $\begin{array}{c}\text { 17/02/2012 } \\
07: 00\end{array}$ & $\begin{array}{c}17 / 02 / 2012 \\
19: 00\end{array}$ & 62.8 & 1012.2 & 93.0 & -1.3 & 1.9 & SW (WWN) \\
\hline G74 & G143 & $\begin{array}{c}17 / 02 / 2012 \\
19: 00\end{array}$ & $\begin{array}{c}18 / 02 / 2012 \\
07: 00\end{array}$ & & 1014.8 & 88.3 & 1.3 & 1.4 & W (WSW, WNW) \\
\hline
\end{tabular}

Note that values of concentration of PM10 were obtained using automatic optoelectronic method and represent 24-h averages. Optoelectronic data for concentration of PM1 are not available

Distribution of the dust on the surface of the filter can be considered as sufficiently homogeneous [45].

Thus, the mass-normalized saturation induced magnetization $M_{\mathrm{s}}$ depends solely on the concentration of ferrimagnetic substance; in case of pure magnetite, $M_{\mathrm{s}}$ would be $90-92 \mathrm{Am}^{2} / \mathrm{kg}$. Saturation remanent magnetization $M_{r s}$ depends on the concentration as well as on grain-size distribution of the ferrimagnetic substances. The ration
$M_{\mathrm{rs}} / M_{\mathrm{s}}$ reflects the squareness of the hysteresis loop and like coercive force $B_{c}$ depends mostly on the grain-size distribution. Coarse, multi-domain particles have low values of both $M_{\mathrm{rs}} / M_{s}$ and $B_{c}$, finer stable single-domain particles show higher values. Finally, ultra-fine, superparamagnetic particles contribute neither to $M_{\mathrm{rs}}$ nor to $B_{\mathrm{c}}$. For more details on these magnetic properties and their meaning, see, e.g., Dunlop and Ozdemir [46]. 


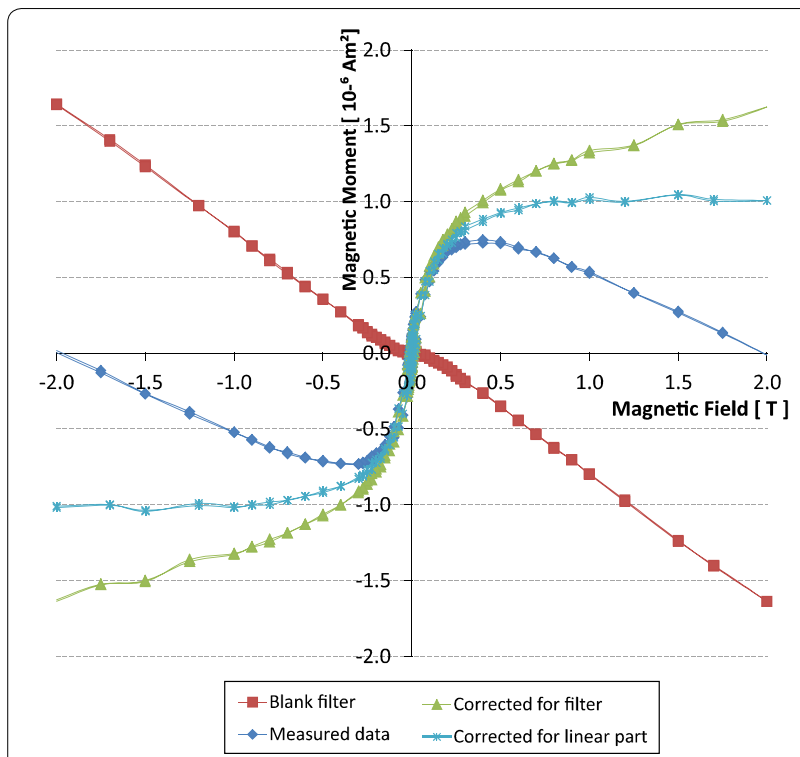

Fig. 2 Example of the measured hysteresis loop and data processing (correction for the background and linear diamagnetic and paramagnetic contributions)

Magnetic properties determined from the hysteresis loops $\left(M_{s}, M_{\mathrm{rs}}\right.$ and $\left.B_{c}\right)$ were compared with the PM10 and PM1 concentrations of the corresponding samples collected by the high-volume samplers using bi-plots and linear regression. Relationship between these variables was assessed using bi-plots, Pearson correlation coefficient $R$, goodness of the fit parameter (coefficient of determination $R^{2}$ ) of linear regression, and statistical significance $p$ value, determined using two-tailed Student's $t$-test.

\section{Results and discussion}

Samples with the corresponding sampling period, concentration of PM10 obtained using automatic optoelectronic method (about 12-h averages, corresponding to the period of sampling by the high-volume samplers), and basic meteorological data are listed in Table 1. Table 2 shows the data of PM10 and PM1 concentrations determined from the dust collected by the highvolume samplers (about 12-h sampling periods) and magnetic properties of the measured specimens (saturation induced magnetization $M_{s}$, saturation remanent magnetizations $M_{\mathrm{rs}}$ and coercive force $B_{c}$ ). It is obvious that except for one specimen (G148, day period towards the end of the sampling), the PM10 concentrations determined by the automatic monitoring system exceeded the allowed limit for daily average of $50 \mu \mathrm{g} / \mathrm{m}^{3}$ [47]. This is in good agreement with the PM10 concentrations determined from the collected samples of PM10, which

Table 2 List of magnetic parameters of the measured specimens and concentrations of the deposited PM10 and PM1

\begin{tabular}{|c|c|c|c|c|c|c|c|c|c|c|}
\hline \multicolumn{6}{|l|}{ PM10 } & \multicolumn{5}{|l|}{ PM1 } \\
\hline Code & $C_{\mathrm{oe}}\left[\mu \mathrm{g} / \mathrm{m}^{3}\right]$ & $C_{\mathrm{hv}}\left[\mu \mathrm{g} / \mathrm{m}^{3}\right]$ & $M_{s}\left[\mathrm{Am}^{2} / \mathrm{kg}\right]$ & $M_{\mathrm{rs}}\left[\mathrm{Am}^{2} / \mathrm{kg}\right]$ & $B_{c}[\mathrm{mT}]$ & Code & $C_{\mathrm{hv}}\left[\mu \mathrm{g} / \mathrm{m}^{3}\right]$ & $M_{s}\left[\mathrm{Am}^{2} / \mathrm{kg}\right]$ & $M_{\mathrm{rs}}\left[\mathrm{Am}^{2} / \mathrm{kg}\right]$ & $B_{c}[\mathrm{mT}]$ \\
\hline G180 & 121.8 & 93.2 & 0.247 & 0.026 & 9.1 & G181 & 52.6 & 0.140 & 0.012 & 7.8 \\
\hline G178 & & 80.5 & 0.200 & 0.026 & 8.4 & G179 & 39.7 & 0.152 & 0.018 & 7.4 \\
\hline G176 & 131.5 & 93.9 & 0.306 & 0.031 & 10.2 & G177 & 49.5 & 0.170 & 0.022 & 9.1 \\
\hline G174 & & 90.2 & 0.284 & 0.029 & 8.9 & G175 & 45.7 & 0.163 & 0.017 & 6.5 \\
\hline G172 & 103.5 & 67.5 & 0.393 & 0.042 & 10.2 & G173 & 30.7 & 0.172 & 0.015 & 12.3 \\
\hline G170 & & 73.2 & 0.467 & 0.046 & 8.7 & G171 & 39 & 0.293 & 0.033 & 7.5 \\
\hline G168 & 228.7 & 95.5 & 0.307 & 0.032 & 10.4 & G169 & 73.6 & 0.104 & 0.010 & 8.3 \\
\hline G166 & & 166.4 & 0.140 & 0.014 & 8.3 & G167 & 103.8 & 0.066 & 0.010 & 5.3 \\
\hline G164 & 180.6 & 150.7 & 0.194 & 0.021 & 7.7 & G165 & 59.8 & 0.113 & 0.012 & 4.8 \\
\hline G162 & & 171.3 & 0.236 & 0.023 & 9.8 & G163 & 70.5 & 0.127 & 0.020 & 8.2 \\
\hline G160 & 147.4 & 140.0 & 0.285 & 0.035 & 10.4 & G161 & 56.6 & 0.175 & 0.018 & 6.8 \\
\hline G158 & & 90.5 & 0.465 & 0.046 & 9.1 & G159 & 40.8 & 0.225 & 0.021 & 9.0 \\
\hline G156 & 127.1 & 56.0 & 0.416 & 0.046 & 11.8 & G157 & 25.9 & 0.243 & 0.031 & 7.8 \\
\hline G154 & & 107.4 & 0.213 & 0.024 & 11.1 & G155 & 49 & 0.098 & 0.014 & 8.4 \\
\hline G152 & 141.7 & 102.9 & 0.421 & 0.040 & 9.2 & G153 & 46.3 & 0.146 & 0.007 & 7.8 \\
\hline G150 & & 87.1 & 0.440 & 0.051 & 10.6 & G151 & 32.8 & 0.244 & 0.026 & 7.4 \\
\hline G148 & 49.5 & 41.7 & 0.953 & 0.100 & 10.4 & G149 & 27.5 & 0.249 & 0.017 & 5.8 \\
\hline G146 & & 33.2 & 10.944 & 0.998 & 9.8 & G147 & 17.9 & 8.448 & 0.779 & 8.5 \\
\hline G144 & 62.8 & 63.4 & 14.971 & 1.277 & 9.8 & G145 & 29.4 & 9.192 & 0.722 & 8.0 \\
\hline G74 & & 39.8 & 14.733 & 1.181 & 9.7 & G143 & 17.9 & 8.636 & 0.719 & 9.4 \\
\hline
\end{tabular}

$C_{\mathrm{oe}}$ : concentration of PM obtained using automatic optoelectronic method ( $24 \mathrm{~h}$ averages), $C_{\mathrm{hv}}$ : concentration of PM obtained using high-volume sampler samples (12 $\mathrm{h}$ averages), $M_{s}$ : saturation induced magnetization, $M_{\mathrm{rs}}$ : saturation remanent magnetization, $B_{c}$ : coercive force 
were well above the limit of $50 \mu \mathrm{g} / \mathrm{m}^{3}$ (except for three specimens at the end of the sampling period). Although the limit of $50 \mu \mathrm{g} / \mathrm{m}^{3}$ represents the daily average and our data correspond to about $12 \mathrm{~h}$ sampling period, we use this allowance limit for reference to emphasize that the sampling period was characterized by significantly increased levels of air pollution.

Saturation-induced magnetization $M_{s}$ of the PM10 specimens varies from 0.140 to $0.467 \mathrm{Am}^{2} / \mathrm{kg}$. One specimen (G148) shows significantly increased value of $0.953 \mathrm{Am}^{2} / \mathrm{kg}$. The average value of $M_{s}$ is $0.351 \mathrm{Am}^{2} /$ $\mathrm{kg}$ (including the G148 specimen). Three specimens (G146, G144 and G74) are considered as outliers, with $M_{s}$ of $10.944,14.971$ and $14.733 \mathrm{Am}^{2} / \mathrm{kg}$, respectively (Table 2). These three values are very high in terms of concentration of magnetite (100\% magnetite would have $M_{s}$ of $90-92 \mathrm{Am}^{2} / \mathrm{kg}$, e.g., [46]. The corresponding saturation remanent magnetization $M_{\mathrm{rs}}$ values are about 10 times lower, ranging from 0.014 to $0.051 \mathrm{Am}^{2} / \mathrm{kg}$, specimen G148 has $M_{\mathrm{rs}}$ of $0.100 \mathrm{Am}^{2} / \mathrm{kg}$. The average value of PM10 $M_{\mathrm{rs}}$ is $0.037 \mathrm{Am}^{2} / \mathrm{kg}$. The three outliers (G146, G144 and G74) have $M_{\mathrm{rs}}$ of $0.998,1.277$ and $1.181 \mathrm{Am}^{2} /$ $\mathrm{kg}$, respectively (Table 2). Correlation of $M_{s}$ and $M_{\mathrm{rs}}$ with the PM10 concentrations is shown in Fig. 3, where striking trend can be observed. Both parameters clearly show negative trend with the PM10 concentration, except for the three outliers (G146, G144 and G74), with the goodness of the fit $R^{2}$ of 0.449 and 0.473 , respectively, suggesting moderate correlation. The Pearson correlation coefficient $R$ is -0.67 and -0.691 , respectively, and the corresponding respective statistical significance $p$ is 0.003254 and 0.002137 .

Very similar observation was done in the case of PM1. $M_{s}$ values vary from 0.066 to $0.293 \mathrm{Am}^{2} / \mathrm{kg}$, with an average of $0.169 \mathrm{Am}^{2} / \mathrm{kg}$. Again, three outliers were identified (G147, G145 and G143), coinciding in the sampling time with those of PM10. These have $M_{s}$ of 8.448, 9.192 and $8.636 \mathrm{Am}^{2} / \mathrm{kg}$, respectively. $M_{\mathrm{rs}}$ values are between 0.007 and $0.033 \mathrm{Am}^{2} / \mathrm{kg}$, with an average of $0.018 \mathrm{Am}^{2} / \mathrm{kg}$. The three outliers have $\mathrm{M}_{\mathrm{rs}}$ of $0.779,0.722$ and $0.719 \mathrm{Am}^{2} /$ $\mathrm{kg}$, respectively (Table 2). Correlation between $M_{\mathrm{rs}}$ and PM1 concentration is depicted in Fig. 4. Similar negative trend as in Fig. 3 can be observed also in the case of PM1, with the $R^{2}$ parameter of 0.586 for $M_{s}$ vs. PM1 (suggesting moderate correlation), and of 0.279 for $M_{\mathrm{rs}}$ vs. PM1, suggesting weak correlation. The Pearson correlation coefficient $R$ is -0.7656 and -0.5286 , respectively, and the corresponding respective statistical significance $p$ is 0.00034 and 0.02915 .

Values of coercive force $B_{c}$ are from 7.7 to $11.8 \mathrm{mT}$ (average of $9.68 \mathrm{mT}$ ) for PM10, and between 4.8 and $12.3 \mathrm{mT}$ (average of $7.81 \mathrm{mT}$ ) for PM1. Only week relationship between $B_{c}$ and concentration of PM10 and

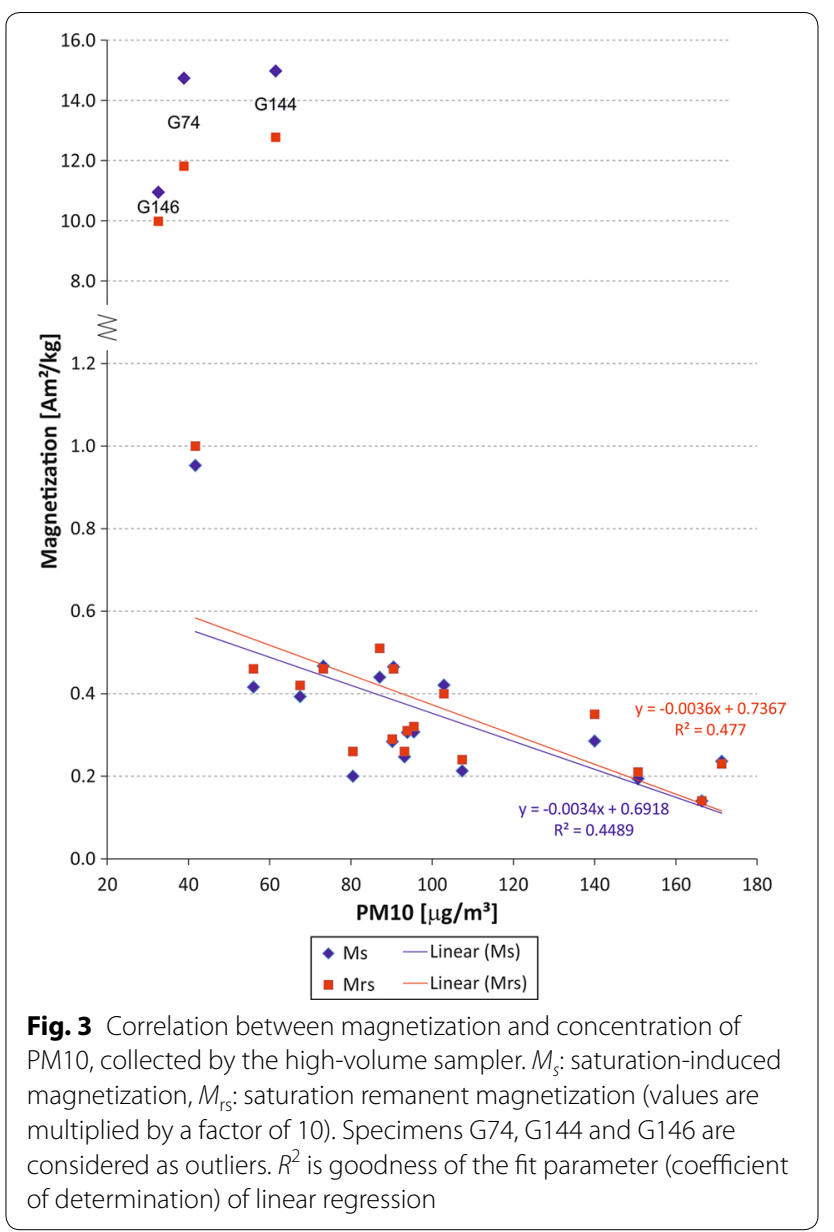

PM1 was observed, with $R^{2}$ of 0.1175 and 0.1693 , respectively (Fig. 5). In this case, the correlation coefficient $R$ is, respectively, -0.3425 and -0.4115 , and the corresponding $p$ value is 0.13893 and 0.07144 .

While the saturation-induced magnetization $M_{s}$ values depend only on the concentration of ferrimagnetic fraction, the remanent magnetization $M_{\mathrm{rs}}$ is affected also by the grain-size distribution. Finer stable singledomain (SSD) particles have significantly higher values than coarse multi-domain (MD) particles. Ultra-fine nano-sized superparamagnetic (SP) particles do not contribute to magnetic remanence. Theoretical value of $M_{\mathrm{rs}} / M_{s}$ for a system of non-interacting SSD particles is 0.5 . In our case, the values for PM10 specimens are from 0.080 to 0.129 , with the average of 0.104 . No outliers were detected in this case and no correlation with PM10 concentration was observed. In case of PM1 specimens, $M_{\mathrm{rs}} / M_{s}$ ranges from 0.047 to 0.154 , the average being 0.104 . These values, along with the very close similarity in relationship between $M_{s}$ and $M_{\mathrm{rs}}$ on one side and PM concentration on the other (Figs. 3 and 4) clearly support the idea that the coarse MD particles dominate 


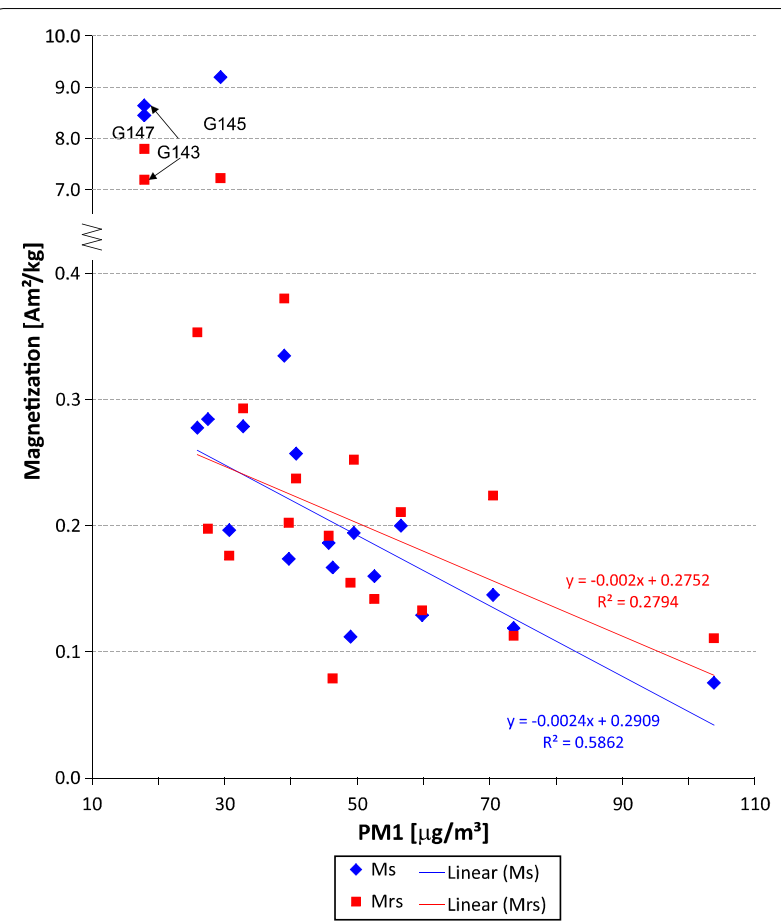

Fig. 4 Correlation between magnetization and concentration of PM1, collected by the high-volume sampler. $M_{s}$ : saturation-induced magnetization, $M_{\mathrm{rs}}$ : saturation remanent magnetization (values are multiplied by a factor of 10). Specimens G143, G145 and G147 are considered as outliers. $R^{2}$ is goodness of the fit parameter (coefficient of determination) of linear regression

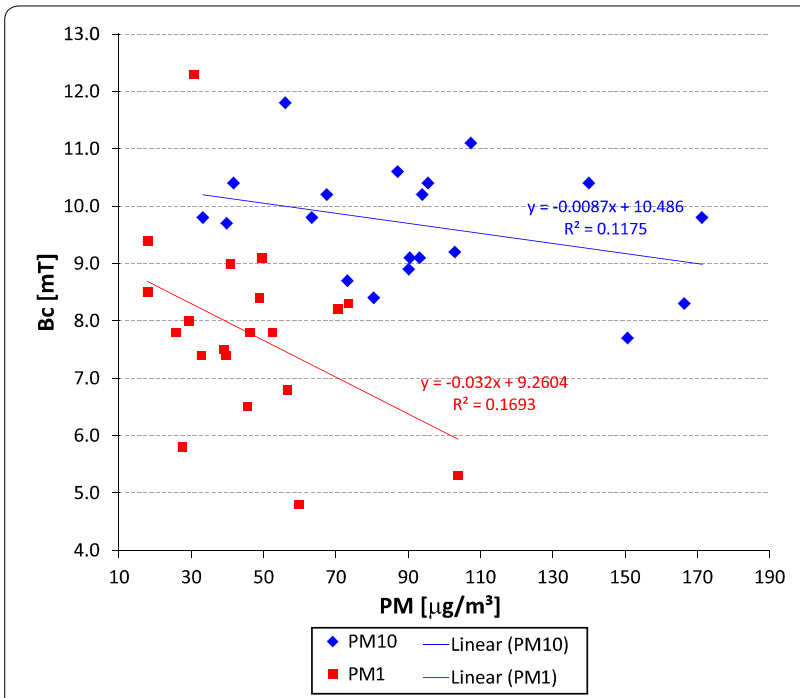

Fig. 5 Correlation between coercive force $B_{c}$ and concentration of PM collected by the high-volume sampler the collected PM samples. However, both the $M_{s}$ and $M_{\mathrm{rs}}$ values of PM10 are about twice of those of PM1 specimens, suggesting that concentration of magnetite in PM10 is about two times higher than in PM1.

Very similar relationship between concentration of ferrimagnetic iron oxides, expressed by $M_{s}$, and concentration of PM10 and PM1 suggest that composition of the particulate matter in both fractions is controlled by the same sources. However, the steel plant in the proximity does not contribute significantly to air pollution in these days. Somewhat weaker relationship between $M_{\mathrm{rs}}$ and PM1 may be explained by higher relative contribution of nano-sized SP magnetite particles, which do not contribute to magnetic remanence. However, situation is completely different during the days when the outliers where collected (at the end of the sampling smoggy period). These specimens show significantly higher values of $\mathrm{M}_{\mathrm{s}}$ and $\mathrm{M}_{\mathrm{rs}}$, while the grain-size dependent $B_{c}$ does not change. This can be interpreted as dominant contribution from the steel plant due to wind direction blowing from the plant to the monitoring station; while in the previous days, it was blowing from the opposite direction.

It is interesting to see that the days with extremely high content of iron oxides (outliers in Figs. 3 and 4) coincide not only with the change in the wind direction, but also with increased average daily humidity and temperature, and decreased air pressure (Table 1). This may indicate worse atmospheric circulation and dispersion of dust. However, elucidating this observation would require much larger data set.

According to the information provided by the steel plant, special measures were in force during the smoggy period. Namely, one baking belt with electrostatic filter in the southern part of the plant stopped, while the remaining three belts with tissue filters in the northern side and one with electrostatic filter in the southern side of the plant continued operation. This resulted in reduction of production of this section by about $15 \%$. Other specific actions were taken in different sections of the plant with the aim to reduce dust emissions. These actions started on 28 January 2012 and lasted until 16 February 2012. Thus, they fully covered our sampling period and we assume they did not affect significantly our results, namely the pronounced change in the observed trend between content of iron oxides and concentration of particulate matter.

We are well aware of the fact that the data deserve more detailed discussion. However, this would require more data, also from different locations with respect to the steel plant, which would enable to study the effect of wind direction, as well as contributions from sources outside the area directly affected by emissions from the steel plant. More discussion now would be only a 
speculation. Our primary aim is to report on negative correlation between magnetic variables and PM, which was not reported until now.

\section{Conclusions}

Magnetic properties of day and night atmospheric dust samples of PM10 and PM1, collected by high-volume samplers during smoggy period of winter 2012 at an industrial monitoring site located close to major steel plant, were analyzed in comparison with the PM concentrations and local weather conditions. Contrary to all the results published until now, our data show negative correlation between the concentration of PM and saturation induced magnetization, which is a measure of concentration of ferrimagnetic iron oxides magnetite and maghemite. Three distinct outliers, which do not follow this trend and show magnetization values about 1.5 orders higher, were collected during days with the westerly's prevailing wind (blowing from major city and steel plant) and changed weather conditions. We believe that the iron-oxides content in the dust collected only during these days was controlled by the emissions from the steel plant. During the other days, the complexity and high number of different pollution sources in the region, combined with the weather conditions (smoggy period), caused that the steel plant did not contribute significantly to air pollution at the nearby monitoring station. These are the first results showing such negative correlation between concentration of iron oxides and dust, which are striking in particular at site close to source of emissions rich in iron oxides. Despite that, our findings do not exclude magnetic methods from environmental monitoring. However, one has to realize that magnetic monitoring is site specific, reflects local conditions, and, as a first step, basic trendlines between the content of iron oxides and pollutants have to be determined at any new site.

\begin{abstract}
Abbreviations
$B_{c}$ : Coercive force in $T$ (magnetic field in direction opposite to previous saturation, at which induced magnetization changes its sign); CHMI: Czech Hydrometeorological Institute; $C_{\text {hv: }}$ Concentration of PM determined from the mass of high-volume sampler samples before and after the sampling (12-h averages); $C_{o e}$ : Concentration of PM obtained using automatic optoelectronic method (24-h averages); $m_{0}$ : Mass of the original sample; $m_{M D}$ : Mass of the collected dust; $\mathrm{M}_{\mathrm{rs}}$ : Saturation remanent magnetization in $\mathrm{Am}^{2} / \mathrm{kg}$ (magnetization in zero field after previous saturation); $\mathrm{M}_{\mathrm{s}}$ : Saturation-induced magnetization in $\mathrm{Am}^{2} / \mathrm{kg}$; $\mathrm{m}_{\mathrm{sp}}$ : Mass of the measured specimen; PM: Particulate matter; PM10: Particulate matter smaller than $10 \mu \mathrm{m}$; PM1: Particulate matter smaller than $1 \mu \mathrm{m} ; R^{2}$ : Goodness of the fit parameter (coefficient of determination) of linear regression; $p$ : Statistical significance, determined using two-tailed Student's t-test.
\end{abstract}

\section{Acknowledgements}

The authors appreciate very much comments of two reviewers, Aldo Winkler and Marcin Szuszkiewicz, which significantly improved the manuscript. We are grateful for the support from the Czech Science Foundation Project No.
P210/10/0554 and Ministry of Education, Youth and Sports of the Czech Republic through an Inter-Vector project LVT19011.

\section{Authors' contributions}

EP designed the study, and made substantial contribution to magnetic measurements, data interpretation and writing the manuscript. HG and AK made substantial contribution to magnetic measurements and data interpretation, and contributed to manuscript preparation. BK made substantial contribution to data interpretation, and contributed to manuscript preparation. HM collected the samples and provided meteorological data, and contributed to manuscript preparation. All authors read and approved the final manuscript.

\section{Funding}

The study was funded by the institutes of the authors, Czech Science Foundation project No. P210/10/0554, and Ministry of Education, Youth and Sports of the Czech Republic through an Inter-Vector project LVT19011.

\section{Availability of data and materials}

The datasets used and/or analyzed during the current study are available from the corresponding author on reasonable request.

\section{Ethics approval and consent to participate}

Not applicable.

\section{Consent for publication}

Not applicable.

\section{Competing interests}

The authors declare that they have no competing interests.

\section{Author details}

${ }^{1}$ Institute of Geophysics, Czech Academy of Sciences, Bočni III/1401, 14100 Prague 4, Czech Republic. ${ }^{2}$ National Institute of Public Health, Šrobárova 48, 10042 Prague 10, Czech Republic. ${ }^{3}$ Public Health Institute Ostrava, Partyzánské nám. 7, 70200 Ostrava, Czech Republic.

Received: 17 July 2020 Accepted: 29 September 2020

Published online: 12 October 2020

\section{References}

1. Muxworthy AR, Matzka J, Petersen N (2001) Comparison of magnetic parameters of urban atmospheric particulate matter with pollution and meteorological data. Atmos Environ 35:4379-4386

2. Muxworthy AR, Matzka J, Davila AF, Petersen N (2003) Magnetic signature of daily sampled urban atmospheric particles. Atmos Environ 37:4163-4169

3. Petrovsky E, Zboril R, Grygar TM, Kotlik B, Novak J, Kapicka A, Grison H (2013) Magnetic particles in atmospheric particulate matter collected at sites with different level of air pollution. Stud Geophys Geod 57:755-770

4. Sagnotti L, Macri P, Egli R, Mondino M (2006) Magnetic properties of atmospheric particulate matter from automatic air sampler stations in Latium (Italy): Toward a definition of magnetic fingerprints for natural and anthropogenic PM10 sources. J Geophys Res-Solid Earth. https://doi. org/10.1029/2006JB004508

5. Sagnotti L, Taddeucci J, Winkler A, Cavallo A (2009) Compositional, morphological, and hysteresis characterization of magnetic airborne particulate matter in Rome. Geochem Geophys Geosyst, Italy. https://doi. org/10.1029/2009GC002563

6. Hofman J, Maher BA, Muxworthy AR, Wuyts K, Castanheiro A, Samson $R$ (2017) Biomagnetic monitoring of atmospheric pollution: a review of magnetic signatures from biological sensors. Environ Sci Technol 51:6648-6664

7. Jordanova NV, Jordanova DV, Veneva L, Yorova K, Petrovsky E (2003) Magnetic response of soils and vegetation to heavy metal pollution-a case study. Environ Sci Technol 37:4417-4424

8. Kardel F, Wuyts K, De Wael K, Samson R (2018) Biomonitoring of atmospheric particulate pollution via chemical composition and magnetic properties of roadside tree leaves. Environ Sci Pollut Res 25:25994-26004 
9. Kardel F, Wuyts K, Maher BA, Hansard R, Samson R (2011) Leaf saturation isothermal remanent magnetization (SIRM) as a proxy for particulate matter monitoring: Inter-species differences and in-season variation. Atmos Environ 45:5164-5171

10. Kardel F, Wuyts K, Maher BA, Samson R (2012) Intra-urban spatial variation of magnetic particles: monitoring via leaf saturation isothermal remanent magnetisation (SIRM). Atmos Environ 55:111-120

11. Maher BA, Moore C, Matzka J (2008) Spatial variation in vehicle-derived metal pollution identified by magnetic and elemental analysis of roadside tree leaves. Atmos Environ 42:364-373

12. Matzka J, Maher BA (1999) Magnetic biomonitoring of roadside tree leaves: identification of spatial and temporal variations in vehicle-derived particulates. Atmos Environ 33:4565-4569

13. Mitchell R, Maher BA (2009) Evaluation and application of biomagnetic monitoring of traffic-derived particulate pollution. Atmos Environ 43:2095-2103

14. Mitchell R, Maher BA, Kinnersley R (2010) Rates of particulate pollution deposition onto leaf surfaces: Temporal and inter-species magnetic analyses. Environ Pollut 158:1472-1478

15. Moreno E, Sagnotti L, Dinares-Turell J, Winkler A, Cascella A (2003) Biomonitoring of traffic air pollution in Rome using magnetic properties of tree leaves. Atmos Environ 37:2967-2977

16. Rodriguez-Germade I, Mohamed KJ, Rey D, Rubio B, Garcia A (2014) The influence of weather and climate on the reliability of magnetic properties of tree leaves as proxies for air pollution monitoring. Sci Tot Environ 468:892-902

17. Zhang CX, Huang BC, Li ZY, Liu H (2006) Magnetic properties of highroad-side pine tree leaves in Beijing and their environmental significance. Chinese Sci Bull 51:3041-3052

18. Jordanova D, Petrov P, Hoffmann V, Gocht T, Panaiotu C, Tsacheva T, Jordanova N (2010) Magnetic signature of different vegetation species in polluted environment. Stud Geophys Geod 54:417-442

19. Lehndorff E, Urbat M, Schwark L (2006) Accumulation histories of magnetic particles on pine needles as function of air quality. Atmos Environ 40:7082-7096

20. Urbat M, Lehndorff E, Schwark L (2004) Biomonitoring of air quality in the Cologne conurbation using pine needles as a passive sampler - Part l: magnetic properties. Atmos Environ 38:3781-3792

21. Brignole D, Drava G, Minganti V, Giordani P, Samson R, Vieira J, Pinho P, Branquinho C (2018) Chemical and magnetic analyses on tree bark as an effective tool for biomonitoring: a case study in Lisbon (Portugal). Chemosphere 195:508-514

22. Chaparro MAE, Chaparro MAE, Castañeda-Miranda AG, Marié DC, Gargiulo JD, Lavornia JM, Natal M, Böhnel HN (2020) Fine air pollution particles trapped by street tree barks: In situ magnetic biomonitoring. Environ Pollut 266:1 15229. https://doi.org/10.1016/j.envpol.2020.115229

23. Vezzola LC, Muttoni G, Merlini M, Rotiroti N, Pagliardini L, Hirt AM, Pelfini M (2017) Investigating distribution patterns of airborne magnetic grains trapped in tree barks in Milan, Italy: insights for pollution mitigation strategies. Geophys J Int 210:989-1000

24. Wuyts K, Hofman J, Van Wittenberghe S, Nuyts G, De Wael K, Samson R (2018) A new opportunity for biomagnetic monitoring of particulate pollution in an urban environment using tree branches. Atmos Environ 190:177-187

25. Zhang CX, Huang BC, Liu QS (2009) Magnetic properties of different pollution receptors around steel plants and their environmental significance. Chinese J Geophys-Chinese Edition 52:2826-2839

26. Zhang CX, Huang BC, Piper JDA, Luo RS (2008) Biomonitoring of atmospheric particulate matter using magnetic properties of Salix matsudana tree ring cores. Sci Tot Environ 393:177-190

27. Chaparro MAE, Lavornia JM, Sinito AM (2013) Biomonitors of urban air pollution: Magnetic studies and SEM observations of corticolous foliose and microfoliose lichens and their suitability for magnetic monitoring. Environ Pollut 172:61-69

28. Kodnik D, Winkler A, Carniel FC, Tretiach M (2017) Biomagnetic monitoring and element content of lichen transplants in a mixed land use area of NE Italy. Sci Tot Environ 595:858-867

29. Marie DC, Chaparro MAE, Irurzun MA, Lavornia JM, Marinelli C, Cepeda R, Bohnel HN, Miranda AGC, Sinito AM (2016) Magnetic mapping of air pollution in Tandil city (Argentina) using the lichen Parmotrema pilosum as biomonitor. Atmos Pollut Res 7:513-520

30. Marie DC, Chaparro MAE, Lavornia JM, Sinito AM, Miranda AGC, Gargiulo JD, Bohnel HN (2018) Atmospheric pollution assessed by in situ measurement of magnetic susceptibility on lichens. Ecol Indic 95:831-840

31. Paoli L, Winkler A, Guttova A, Sagnotti L, Grassi A, Lackovicova A, Senko D, Loppi S (2017) Magnetic properties and element concentrations in lichens exposed to airborne pollutants released during cement production. Environ Sci Pollut Res 24:12063-12080

32. Salo H, Bucko MS, Vaahtovuo E, Limo J, Makinen J, Pesonen LJ (2012) Biomonitoring of air pollution in SW Finland by magnetic and chemical measurements of moss bags and lichens. J Geochem Explor 115:69-81

33. Winkler A, Caricchi C, Guidotti M, Owczarek M, Macrì P, Nazzari M, Amoroso A, Di Giosa A, Listrani S (2019) Combined magnetic, chemical and morphoscopic analyses on lichens from a complex anthropic context in Rome, Italy. Sci Tot Environ 690:1355-1368

34. Winkler A, Contardo T, Vannini A, Sorbo S, Basile A, Loppi S (2020) Magnetic emissions from brake wear are the major source of airborne particulate matter bioaccumulated by lichens exposed in Milan (Italy). Appl Sci 10:2073. https://doi.org/10.3390/app10062073

35. Fabian K, Reimann C, McEnroe SA, Willemoes-Wissing B (2011) Magnetic properties of terrestrial moss (Hylocomium splendens) along a north-south profile crossing the city of Oslo, Norway. Sci Tot Environ 409:2252-2260

36. Limo J, Paturi P, Makinen J (2018) Magnetic biomonitoring with moss bags to assess stop-and-go traffic induced particulate matter and heavy metal concentrations. Atmos Environ 195:187-195

37. Salo H, Berisha AK, Makinen J (2016) Seasonal comparison of moss bag technique against vertical snow samples for monitoring atmospheric pollution. J Environ Sci 41:128-137

38. Salo H, Makinen J (2014) Magnetic biomonitoring by moss bags for industry-derived air pollution in SW Finland. Atmos Environ 97:19-27

39. Salo H, Makinen J (2019) Comparison of traditional moss bags and synthetic fabric bags in magnetic monitoring of urban air pollution. Ecol Indic 104:559-566

40. Salo H, Paturi P, Makinen J (2016) Moss bag (Sphagnum papillosum) magnetic and elemental properties for characterising seasonal and spatial variation in urban pollution. Int J Environ Sci Technol 13:1515-1524

41. Vukovic G, Urosevic MA, Goryainova Z, Pergal M, Skrivanj S, Samson R, Popovic A (2015) Active moss biomonitoring for extensive screening of urban air pollution: Magnetic and chemical analyses. Sci Tot Environ 521:200-210

42. Vukovic G, Urosevic MA, Tomasevic M, Samson R, Popovic A (2015) Biomagnetic monitoring of urban air pollution using moss bags (Sphagnum girgensohnii). Ecol Indic 52:40-47

43. Rachwal M, Rybak J, Rogula-Kozlowska W (2018) Magnetic susceptibility of spider webs as a proxy of airborne metal pollution. Environ Pollut 234:543-551

44. CHMI (2012) Znečištění ovzduší na území České republiky v roce 2012 (Air pollution over the territory of the Czech Republic in 2012). Annual Report. Czech Hydrometeorological Institute, Prague, https://porta I.chmi.cz/files/portal/docs/uoco/isko/grafroc/groc/gr12cz/obsah.html. Accessed 23 Sept 2020 (in Czech)

45. Sysalova J, Kucera J, Kotlik B, HavranekV (2002) Quality control materials for the determination of trace elements in airborne particulate matter. Anal Bioanal Chem 373:195-199

46. Dunlop DJ, Ozdemir O (1997) Rock magnetism: fundamentals and frontiers. Cambridge University Press, Cambridge

47. WHO (2006) WHO Air quality guidelinesfor particulate matter, ozone, nitrogendioxide and sulfur dioxide. World Health Organization, Geneva

\section{Publisher's Note}

Springer Nature remains neutral with regard to jurisdictional claims in published maps and institutional affiliations. 